\title{
Tension-free vaginal tape (TVT): our modified technique- effective solutions for postoperative TVT correction
}

Published online: 8 April 2004

(C) Springer-Verlag Berlin / Heidelberg 2004

\begin{abstract}
Tension-free vaginal tape (TVT) is nowadays an established operation for the treatment of stress urinary incontinence. In this article, we will demonstrate our standardized TVT procedure and ways of possible postoperative correction. A tight vaginal tape can be individually expanded by a Prolene-interponate within days and also years after surgery. On the other hand, we developed a technique to shorten a loose vaginal tape. Moreover, we will discuss our approaches in the case of an eroded Prolene tape, local estrogen therapy, tape padding with vaginal tissue and blunt removal of the tape by a small vaginal incision.
\end{abstract}

\section{Introduction}

Tension-free vaginal tape (TVT) is nowadays an established operation for the treatment of stress urinary incontinence. In this article, we will demonstrate our standardized TVT procedure and ways of possible postoperative correction. A tight vaginal tape can be individually expanded by a Prolene-interponate within days and also years after surgery. On the other hand, we developed a technique to shorten a loose vaginal tape. Moreover, we will discuss our approaches in the case of an eroded Prolene tape, local estrogen therapy, tape padding with vaginal tissue and blunt removal of the tape by a small vaginal incision.

A change has taken place in the paradigm. Nowadays, the Burch colposuspension [1, 2] is replaced by TVT, described by Ulmsten [3] as a gold standard for the surgical treatment of stress urinary incontinence. Over the last 8 years, TVT has shown great results. We see cure rates of approximately $87 \%[4,5,6,7,8,9]$. This trend is expected to continue in the future. Compared to other techniques of colposuspension, the outcome of tension-

\footnotetext{
W. Zubke · I. V. Gruber · K. Gardanis · D. Wallwiener (

Department of Gynecology and Obstetrics,

University of Tübingen,

Tübingen, Germany

e-mail: diethelm.wallwiener@med.uni-tuebingen.de
}

free vaginal tape can be ranked as at least equally successful $[10,11,12,13,14,15,16,17,28]$. Based on the integral theory of stress urinary incontinence, Petros and Ulmsten developed an innovative technique to compensate for the insufficiency of pubourethral ligaments [3]. Therefore, an alloplastic sling is placed tension-free underneath the urethra under local anesthesia. The invasion of endogenous connective tissue into the synthetic material of the mesh restores consistency at the level of the pubourethral ligaments. Moreover, the tension of the sling can be individually adjusted during surgery depending on the urinary function of each patient. Despite the fact that this minimally invasive procedure is an outpatient treatment, it is frequently connected with a short hospitalization period. TVT can be combined with other vaginal or laparoscopic surgeries. In the following, we will demonstrate the standardized TVT technique [29] used at the University of Tübingen.

\section{Materials and methods}

Steps

Step 1

The patient is placed in a horizontal dorsolithotomy position. After desinfection, the bladder is emptied via a transurethral Foley catheter. Local anesthetics (0.5\% lidocaine and suprarenin) are injected into the abdominal skin, just above the mons pubis and downwards along the back of the pubic bone to the space of Retzius (Fig. 1). Two small incisions are made above the superior rim of the pubic bone, where the TVT needles will be brought up later. Then we apply local anesthetics in the vaginal wall sub- and paraurethrally, approximately $1 \mathrm{~cm}$ beneath the urethral meatus. By fingertip control, we guide a long, bent needle around the pubic bone in order to infiltrate vaginally the space of Retzius and the fascia pelvina. Local anesthetics add up to $50-80 \mathrm{ml}$ and are often supplemented by intravenous sedatives (e.g., remifentanil and ultiva).

Step 2

The urethra and bladder neck will be identified by a straight metallic handle inserted in the Foley catheter. A 1-cm-long sagittal 


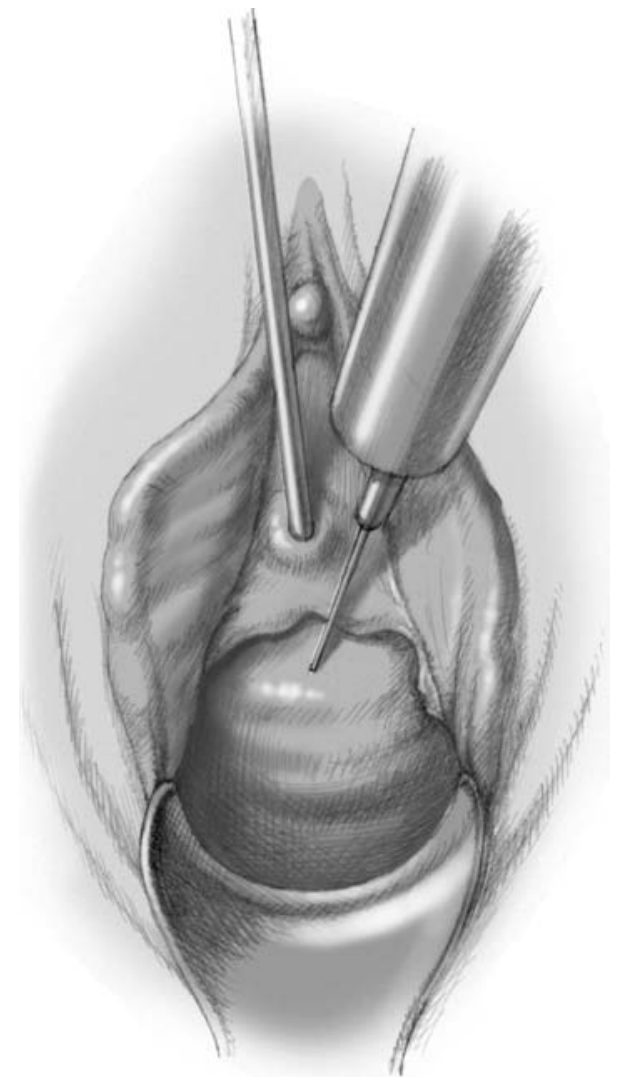

Fig. 1 Step 1. Local anesthesia: here we inject $5 \mathrm{ml}$ of $0.5 \%$ lidocain solution below the wall of the vagina in the region of the small incision for step 2

incision is made in the midline of the suburethral vaginal wall, starting about $1.5 \mathrm{~cm}$ beneath the outer urethral meatus (Fig. 2). In order to avoid postoperative voiding difficulties (e.g., urge incontinence), the incision should be as sparing as possible, as paraurethal tissue must not be injured.

\section{Step 3}

Laterally from this incision, a blunt, strictly subvaginal dissection is made to each side of the urethra by the Lexer scissor (Fig. 3). These two tunnels, with the exact width of the Prolene tape, have to be created underneath the fascia vaginalis so that the inserted Prolene mesh will not affect the vaginal mucosa and consequently cause problems.

\section{Step 4}

The straight metallic inserter helps to lateralize the urethra and bladder to the left, dorsal side when the TVT needle is inserted into the prepared paraurethral right incision (Fig. 4). First, the tip of the needle is directed in a bent line through the right subvaginal tunnel towards the urogenital diaphragma and then is turned precisely sagittally.

\section{Step 5}

By lowering the handle of the needle and under fingertip control, we perforate the endopelvic fascia. The needle is guided through the retropubic space along the backside of the pubic bone, through the space of Retzius, towards the abdominal skin incision, where it

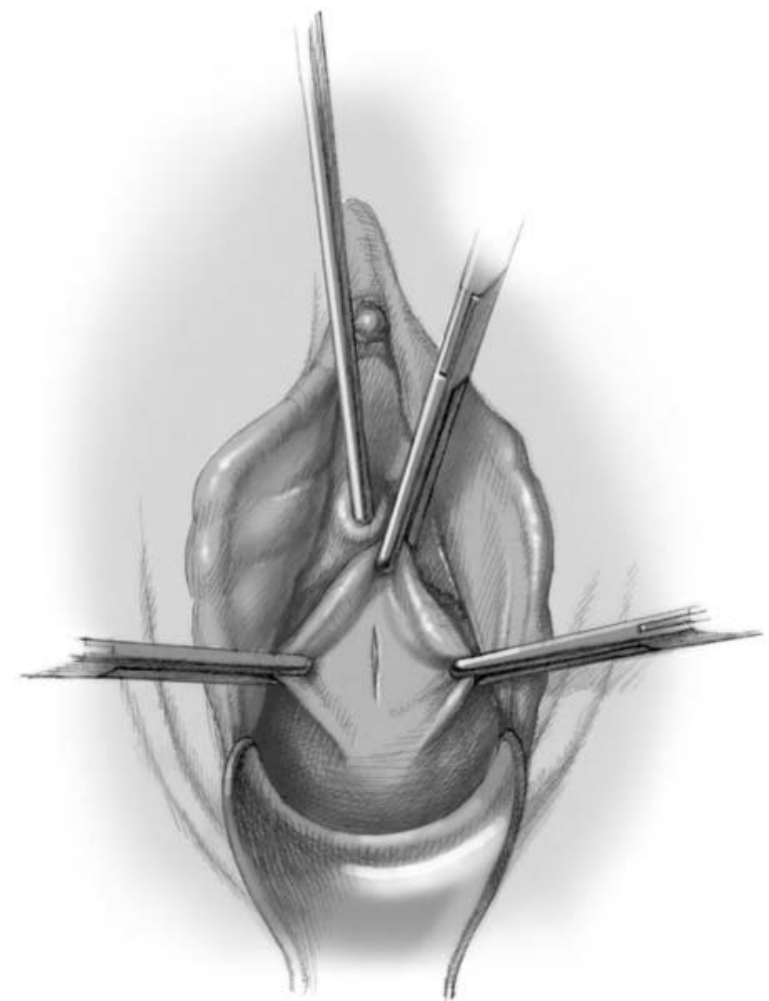

Fig. 2 Step 2. At a distance of about $1 \mathrm{~cm}$ from the meatus urethrae, we cut an incision about $1 \mathrm{~cm}$ in the midline of the wall of the vagina

is brought up. There it remains in situ, and the metallic handle is disconnected (Fig. 5). It is important to guide the needle (in an acute angle) along the os pubis by "shaving"' the back of the bone (Fig. 6). This procedure prevents complications such as perforation of the bladder, especially after previous surgeries with postoperative scarring around the cavum Retzii.

Before we begin with cystoscopy to confirm an intact bladder, steps 4 and 5 are repeated with the second needle on the left side of the urethra. Our modified method saved time and did not show any disadvantages during the last 800 TVT procedures performed.

Step 6

The straight metallic catheter guide is removed, and the bladder is prepared for cytoscopy with $400 \mathrm{ml}$ saline solution. Cytoscopy is performed with a 70-degree Storz optic, so all areas of the bladder mucosa can be inspected (Fig. 7). In case of perforation, we have to remove the TVT needle vaginally and start a new passage, again followed by cystoscopy.

\section{Step 7}

In case of an intact bladder, needles are pulled completely through the abdominal skin and disconnected from the Prolene tape (Fig. 8). Kocher clamps will fix the ends of the tape. The TVT sling should lie flat against the surface of the mid-urethra. Now we can start the tension test. The patient is asked to cough vigorously to check urinary continence. In the presence of urinary leakage, the ends of the slings are slightly pulled until continence is confirmed. Importantly, the sling should only be loosely located around the urethra, without tension and elevation. For proper adjustment, we use Cooper scissors placed between the tape and the urethra. The 


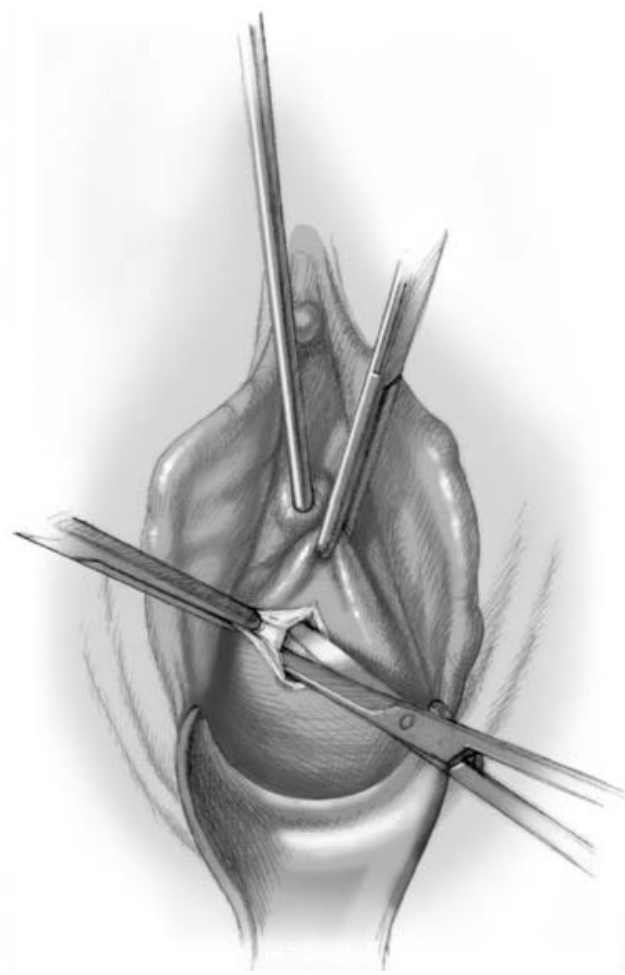

Fig. 3 Step 3. With Lexer scissors, a tunnel is undermined below the fascia of the vagina towards the ramus of ischium

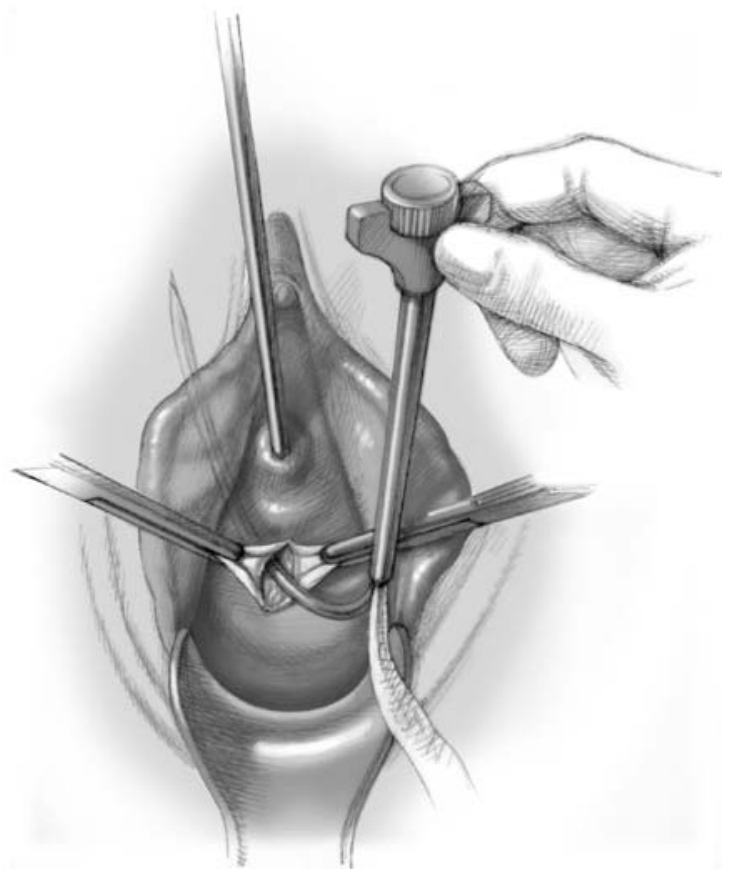

Fig. 4 Step 4. The TVT needle is carefully inserted into the preformed tunnel

plastic sheaths are removed, and the abdominal ends of the tape are cut subcutaneously. No fixation is required to maintain the tape. The vaginal incisions are sutured by single absorbable Vicryl knots, and the abdominal skin incisions are closed by adhesive tape. We

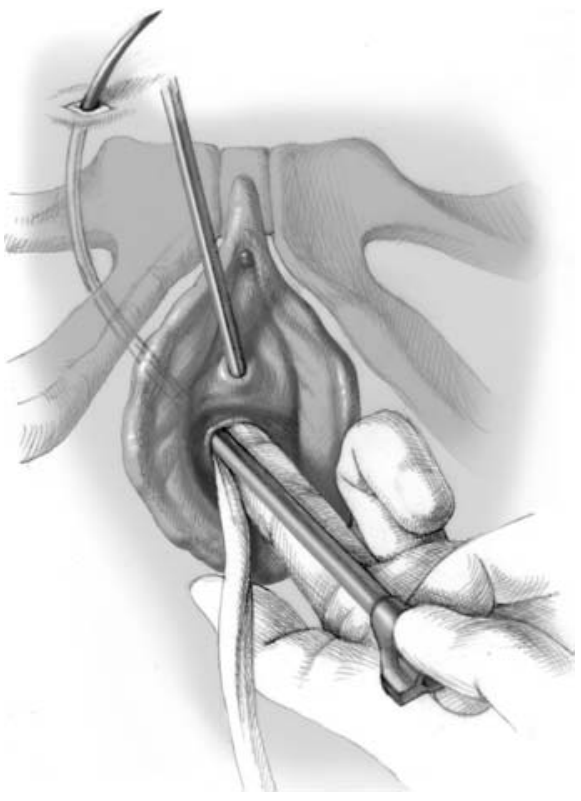

Fig. 5 Step 5. Now, the TVT needle is pushed around the symphysis in a straight, sagittal direction and the top of the needle is pierced through the skin of the mons pubis

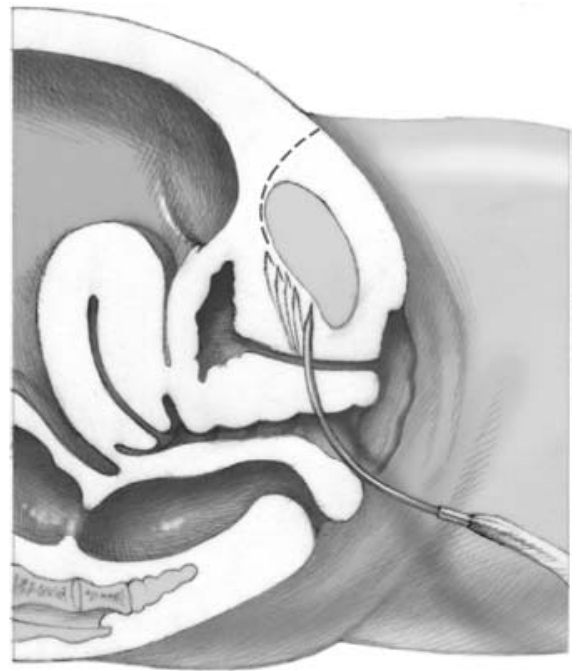

Fig. 6 The top of the needle has to touch the backside of the symphysis, respectively the pubis, to prevent lesions of the bladder

prefer the bladder not to be emptied for $2 \mathrm{~h}$. A filled bladder prevents postoperative hemorrhage by compressing the retropubical space. Our complication rate of postoperative bleeding is $0.3 \%$ and therefore much lower than previously published data. One gram of cefotiam (Spizef) is administered peri-operatively. The low complication rates of TVT can be compared to those of colposuspension $[10,20]$.

\section{Treatment of complications}

Perforation of the bladder (up to $11.6 \%$ ) $[4,7,8,21,22,23]$ and bleeding (up to $3.3 \%$ ) $[9,21,22,24]$ are the most common complications seen during surgery. Voiding difficulty (up to 17\%) [4, $21,22,23$ ] is the most common postoperative complication, which 


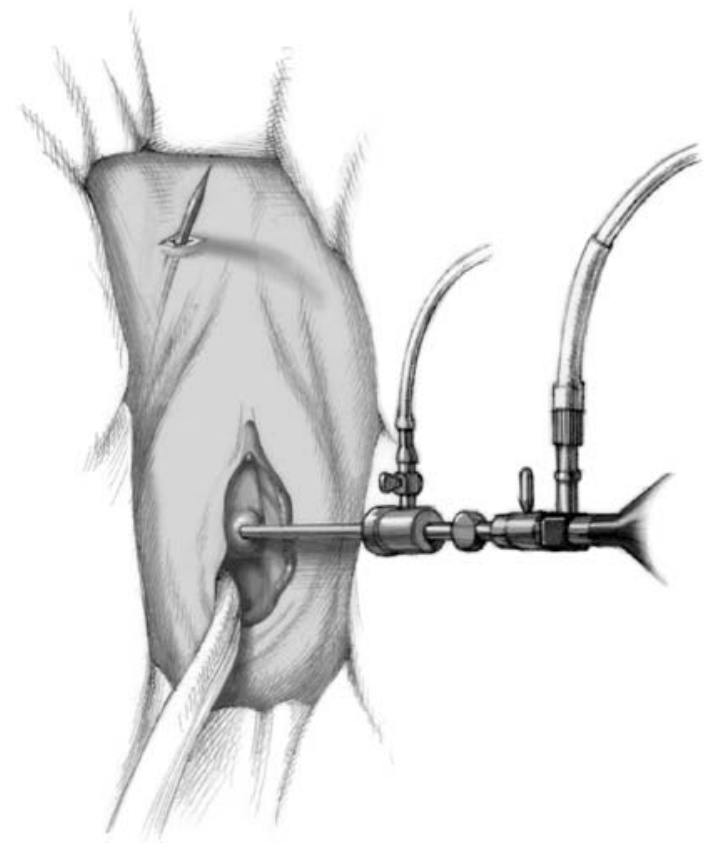

Fig. 7 Step 6. After pushing the needle or both needles around the pubis and through the surface of the mons pubis, cystoscopy has to be carried out

often leads to reoperation [24]. If the sling is placed too tightly around the urethra (Fig. 9), the reduced inclination angle of less than 45 degrees raises the risk of urinary retention, diagnosed by sonography.

The reason for a tense tape doesn't have to be just iatrogenic. As the structure of the Prolene mesh retains traction, it risks of postoperative obstruction and elevation of the urethra, although the sling was placed correctly. For example, the removal of the plastic sheets can cause intraoperative traction within the tape structure, which is postoperatively transferred to sling around the urethra. Therefore, repeated intraoperative adjustments, such as loosening or tightening of the same sling, should be avoided.

In the case of urinary retention $(>100 \mathrm{ml})$ and/or a too tightly placed TVT (diagnosed by sonography), we proceed as follows. (We no longer use the common methods, such as dilation of the urethra [25] or extension of the tape by a Hegar handle, which narrows the tape and reduces mesh stability.)

Loosening of the TVT with local anesthesia and/or sedatives (i.v.)

In order to expose the Prolene tape, we have to remove the Vicryl sutures used for suburethral colpotomy (Fig. 10). Then, one side of the sling is grasped by an Overhold clamp. While the patient is asked to cough, the careful loosening of the TVT can proceed, with the surgeon always paying attention not to overdo the correction. In most of our cases, loosening of the Prolene tape was successful. However, tape materials other than the TVT Prolene mesh caused difficulty because of their different mesh structures. After the successful correction of the TVT, colpotomy can be closed in the normal fashion. Loosening of the TVT as described is only possible within the first 14 days after the operation. But what happens if the tape is too tight and the patient shows symptoms (e.g., pain or dyspareunia and/or urinary retention) after weeks, months or even years? The literature offers two solutions. The first is complete removal of the tape and insertion of a newly adjusted TVT [26]. This procedure is connected with considerable tissue trauma and does not guarantee the postoperative period without complications. The second is suburethral splitting of the tape [27]. This procedure is recommended at the earliest 2 months post-surgery as the tissue

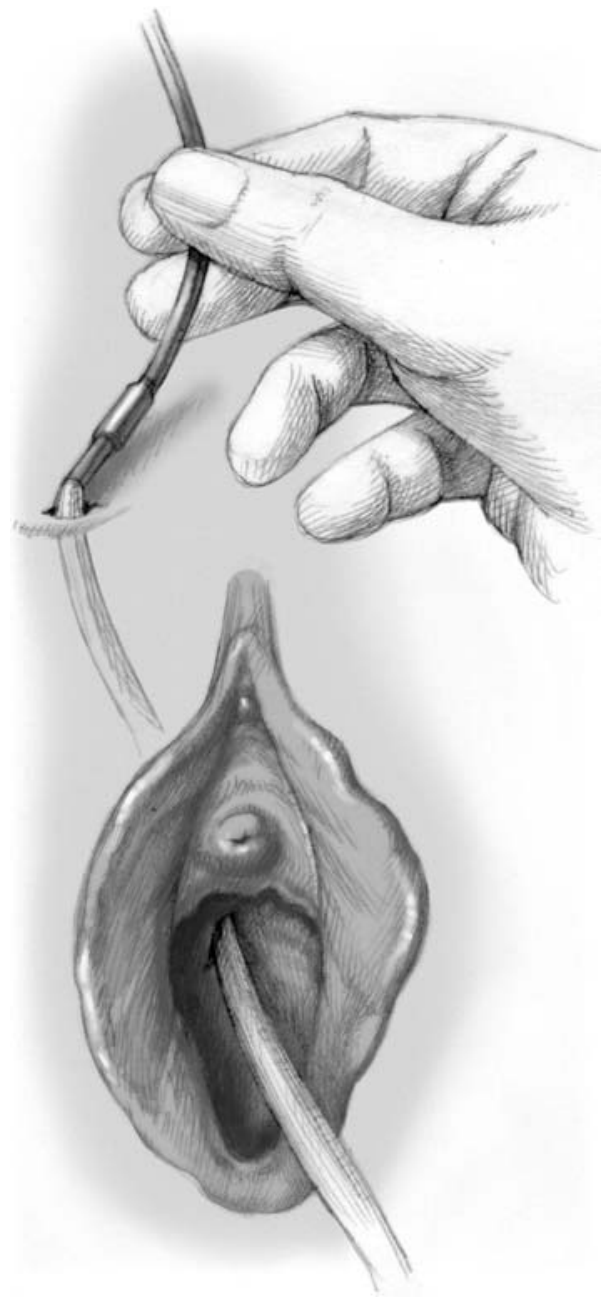

Fig. 8 Step 7. If there is no lesion of the bladder, the TVT needle is pulled and the mesh of the TVT comes to the surface of the mons pubis

should have reached a certain consistency to reduce the reappearance of stress urinary incontinence. Therefore, we developed an individually adjusted method of tape extension by a Prolene-interponate.

\section{Extension of TVT length}

Step 1

The vaginal mucosa is dissected over a horizontal distance of $1.5 \mathrm{~cm}$, just underneath the placed tape (Fig. 11). The exposed sling is carefully detached from connective tissue and mobilized to each side (about $3 \mathrm{~cm}$ ). As soon as Overhold clamps fix the ends of both sides, the tape can be cut in half suburethrally.

Step 2

A $1.5 \mathrm{~cm} \times 6.5-\mathrm{cm}$ (width $\times$ length) Prolene-interponat is sewn on both tape ends, overlapping at a distance of $2 \mathrm{~cm}$ (Fig. 12). A submerged single Vicryl knot is used. 


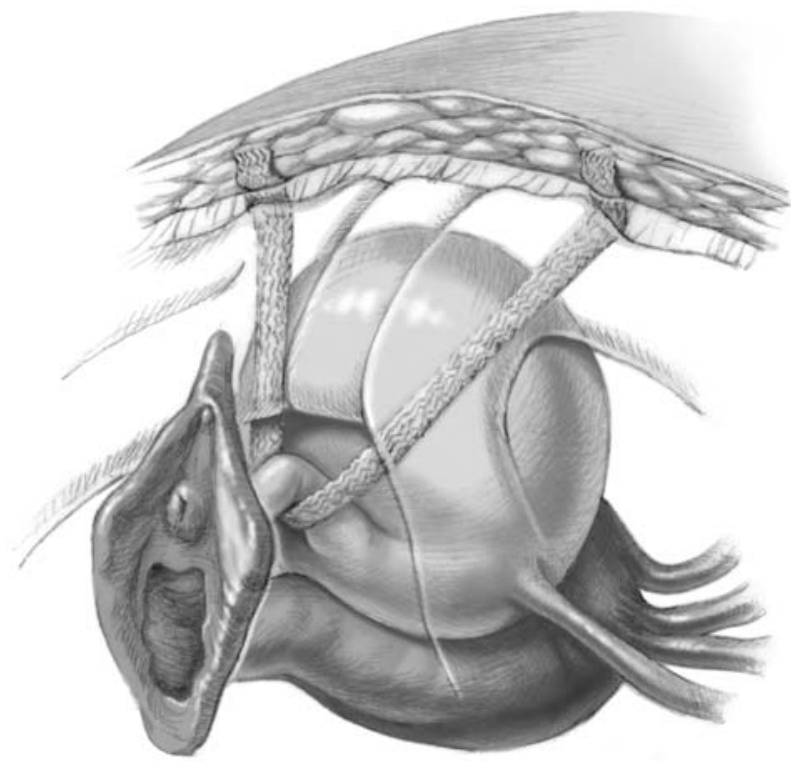

Fig. 9 A sling that is placed too tightly can elevate the urethra and cause urinary retention and dyspareunia

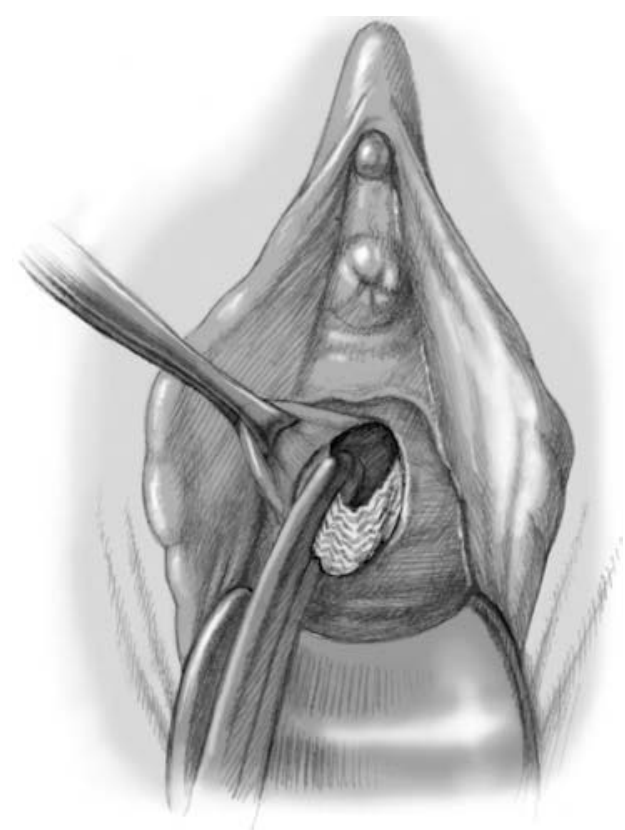

Fig. 10 Release of the TVT. Under local anesthesia, the small colpotomy is opened and the TVT is drawn off by an Overhold clamp for about 0.5 to $1.5 \mathrm{~cm}$

\section{Step 3}

We test the tension of the newly adjusted tape, control bleeding and resuture the vaginal mucosa (Fig. 13). Antibiotics are administered peri-operatively. So far, we have carried out 12 TVT extensions. The patients were followed up for 18 months by tonometry and sonography, which showed good clinic results. However, in three cases we saw tape erosion. In one case, it could be resolved by local estrogen therapy. In another case, estrogen therapy was not successful. Therefore, we had to expose the tape and cover it by mobilized vaginal tissue. After that, a postoperative period of 1 year

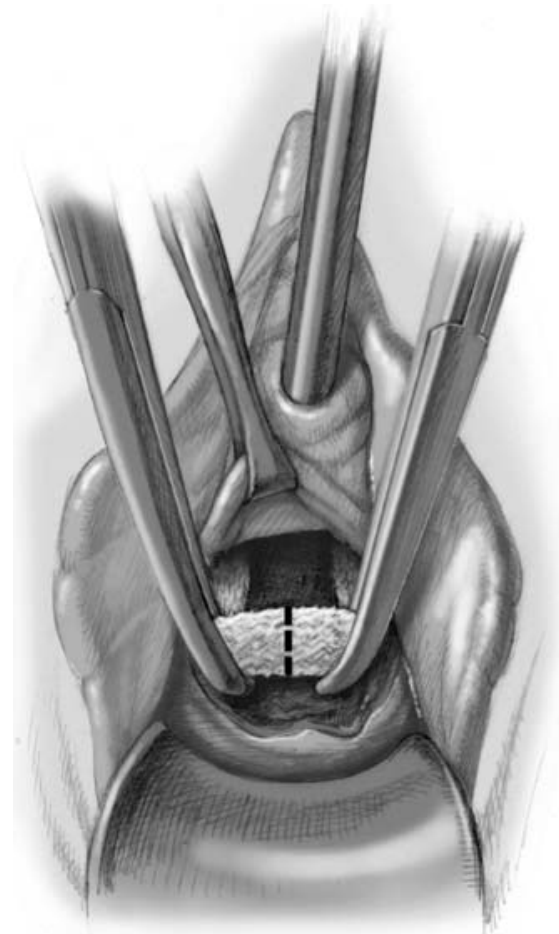

Fig. 11 Step 1. The wall of the vagina is split just below the urethra for $1.5 \mathrm{~cm}$. The TVT is prepared, held on both sides by an Overhold clamp and cut in the middle

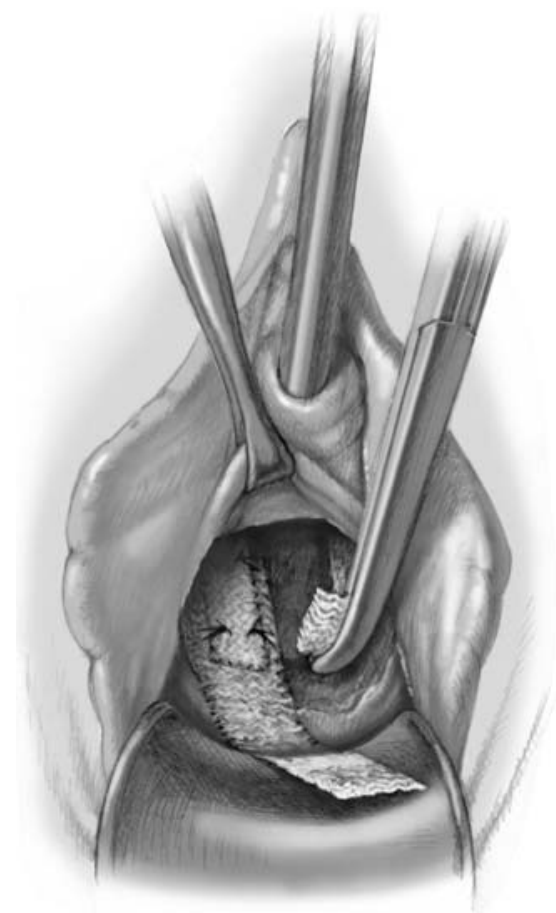

Fig. 12 Step 2. A Prolene mesh is individually adapted, positioned behind the ends of the TVT and fixed with Prolene sutures to the TVT 


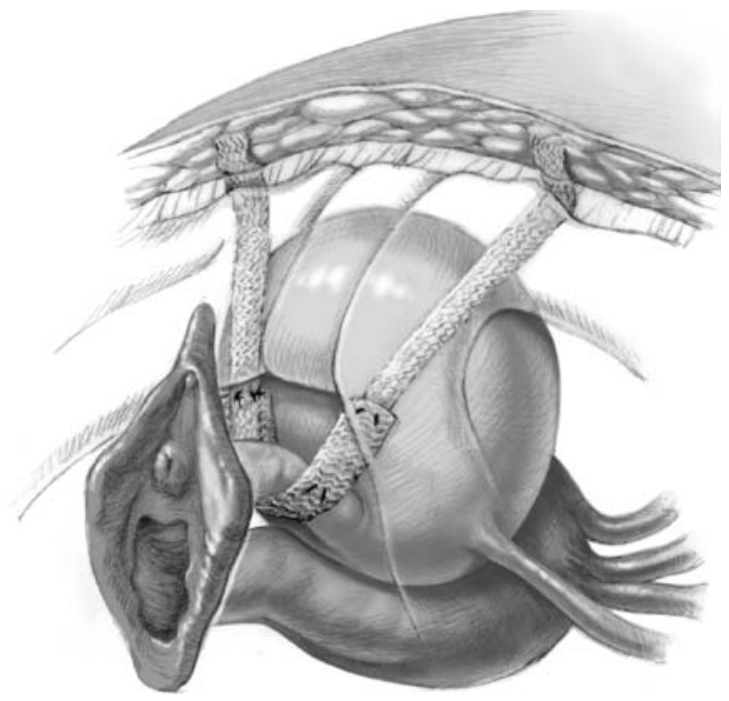

Fig. 13 Step 3. The tension of the newly adapted TVT is checked, and the small colpotomy is closed

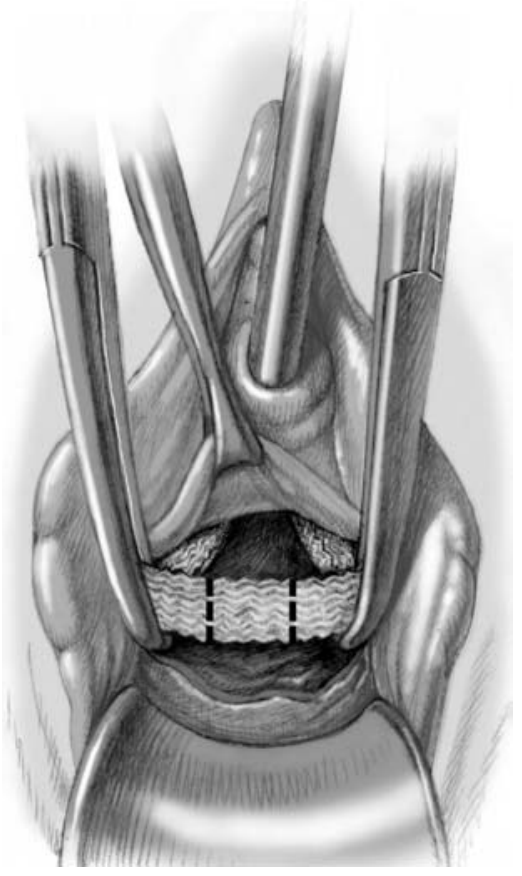

Fig. 14 Step 1. The wall of vagina just below the urethra is split, the TVT is prepared and fixed with Overhold clamps. An individually adapted portion of the TVT is cut out

was free of complications. One patient with dyspareunia was treated in another clinic, where the TVT was completely removed. Here, we have no data concerning the outcome. From our experience, we now recommend a persistent local estrogen therapy after every TVT extension. Moreover, if possible, the TVT should be covered with additional mobilized vaginal tissue during closure of the colpotomy.

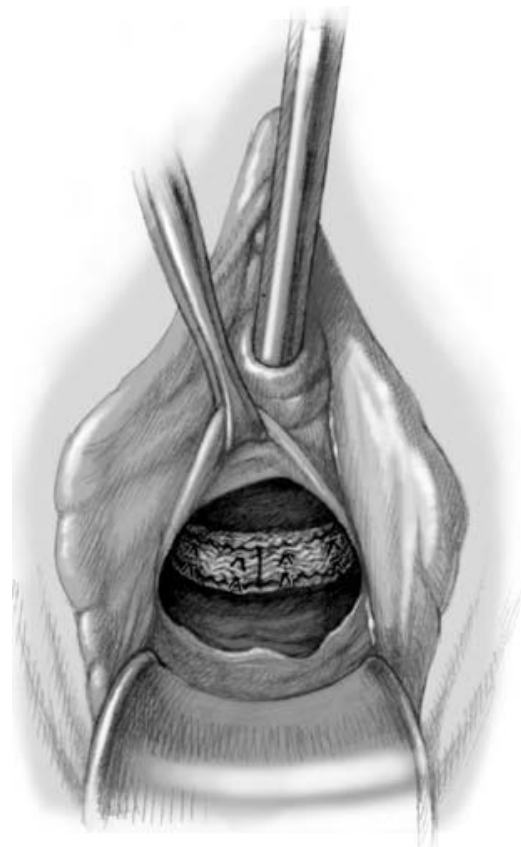

Fig. 15 Step 2. A Prolene mesh is underlined to the TVT and fixed to it with Prolene sutures. The colpotomy is closed be Vicryl sutures

\section{Reduction of TVT length}

If the tape is placed too loosely around the urethra, TVT is ineffective. Stress urinary incontinence will persist and makes a TVT correction necessary by reducing the length.

Step 1

Again we expose the tape, separate it from connective tissue and fix it with two Overhold clamps (Fig. 14). Next, we excise a piece of the suburethral sling $(\sim 1 \mathrm{~cm})$.

Step 2

A Prolene-interponate $(4 \mathrm{~cm} \times 1.5 \mathrm{~cm})$ is put behind the transected tape so that the individually corrected ends can be sewed on by single knots (Fig. 15). Again, the general closure of the vaginal mucosa follows.

\section{Results}

Up to now, we have applied this technique in four cases. The clinical results, also checked by tonometry and sonograpy, were satisfying. Within the follow-up period of 12 months, we did not see any tape erosions. A rare complication of TVT is the irritation of the bladder. Fourteen months after the TVT procedure, one patient presented with bleeding, which was identified as bladder hemorrhage. Cystoscopy showed fibrin layers and scarring in the subpubical area. Perforation of the bladder and the appearance of the Prolene tape could not be confirmed. Obviously relapsing tape erosions affected the 
bladder, which, however, healed spontaneously. Therefore, we uncovered the TVT beneath the urethra by a small incision, proceeded with blunt dissection of both ends towards the mons pubis and removed the tape. Histology and further check-ups did not show any pathology.

In one case, painful granulomas appeared around the tape ends; this was seen in the area of the mons pubis. By uncovering the tape ends under local anesthesia, the pathological tissue was excised. The symptoms resolved completely, and no voiding difficulties were seen afterwards.

\section{Discussion}

The TVT procedure was introduced, perfected and propagated by Ulmsten [3]. Our modified, well-tried technique at the University of Tübingen (Department of Gynecology and Obstetrics) approaches the aspects of time and money. The usage of $21-\mathrm{CH}$ instead of $18-\mathrm{CH}$ urinary catheters allows for the faster filling and emptying of the bladder. Moreover, we first insert both TVT needles in succession and then perform cystoscopy. This saves time. It is argued that the simultaneous insertion of both needles requires larger incisions with the risk of more periurethral tissue trauma. This in turn raises the risk of postoperative de novo urge incontinence. However, we couldn't confirm this complication at our clinic.

The postoperative correction of a fixed tape was always a problem in the past. Although there are now new tape structures out on the market (e.g., Remeex), which are propagated as easily adjustable after surgery, we continued with the Prolene mesh because of its positive features. Therefore, we developed techniques for TVT reduction and extension with a Prolene-interponate as described. That way we could stay with the same elastic net structure, distributing equal adhesive forces. Tape erosions are a problem with Prolene, but there are ways of successful surgical repair. It should be noted that mostly older patients with several previous operations are treated with TVT. The preceding interventions lead to bradytropic and vulnerable tissue, which is prone to erosion. In these cases, we recommend padding with vaginal tissue and a prophylactic estrogen therapy, applied locally.

In the rare cases of bladder erosion, the tape should be completely removed. This is possible by a minimally invasive operation (blunt preparation through a small vaginal incision).

The occurrence of painful granulomas, as seen in one of our TVT cases, is not described in the literature. However, they could be excised easily under local anesthesia. In general, TVT improved the treatment for stress urinary incontinence extensively. Because of the high incidence of this procedure, typical but rare complications can't be avoided. Therefore, in this article we showed effective, minimally invasive solutions for TVT correction.

\section{References}

1. Burch JC (1961) Urethrovaginal fixation to Cooper's ligament for correction of stress incontinence, cystocele and prolapse. Am J Obstet Gynecol 81:281-290

2. Burch JC (1968) Cooper's ligament urethrovesical suspension for stress incontinence. Am J Obstet Gynecol 100:764-774

3. Ulmsten U, Henriksson L, Johnsson P, Varhos G (1996) An ambulatory surgical procedure under local anesthesia for treatment of female urinary incontinence. Int Urogynecol J 7:81-86

4. Ulmsten U, Johnson P, Rezapour M (1999) A three-year follow-up of tension-free vaginal tape for surgical treatment of female stress urinary incontinence. Br J Obstet Gynecol 106: 345-350

5. Olsson I, Kroon U (1999) A three-year postoperative evaluation of tension-free vaginal tape. Gynecol Obstet Invest 48:267-269

6. Nilsson CG (1998) The tension-free vaginal tape procedure (TVT) for treatment of female urinary incontinence. A minimally invasive surgical procedure. Acta Obstet Gynecol Scand 77 [Suppl 168]:34-37

7. Ulmsten U, Falconer C, Johnson P et al (1998) A multicenter study of tension-free vaginal tape (TVT) for surgical treatment of stress urinary incontinence. Int Urogynecol J 9:210-213

8. Moran PA, Ward KL, Johnson D, Smirni WE, Hilton P, Bibby J (2000) Tension-free vaginal tape for primary genuine stress incontinence: a two-centre follow-up study. BJU Int 86:39-42

9. Nilsson CG, Kuuva N, Falconer C, Rezapour M, Ulmsten U (2001) Long-term results of the tension-free vaginal tape (TVT) procedure for surgical treatment of female stress urinary incontinence. Int Urogynecol J [Suppl 2]:5-8

10. Mainprize TC, Drutz HP (1988) The Marchall-MarchettiKrantz procedure: a critical review. Ostet Gynecol Surv 43: 724-729

11. Park GS, Miller EJ (1988) Surgical treatment of stress incontinence: a comparison of the Kelly Plication, MarshallMarchetti-Kantz and Pereyra Procedure. Obst Gyn 71:575-579

12. Maleika-Rabe A, Wallwiener D, Grischke EM, Solomayer E, Bastert G (1998) Langzeitergebnisse und Deszensuschirugie an der Universitäts-Frauenklinik Heidelberg 1980-1992. Zntralbl Gynäkol 120:106-112

13. Maleika-Rabe A, Wallwiener D, Grischke EM, Solomayer E, Bastert G (1998) Langzeitergebnisse der Inkontinenz- und Deszensuschirugie unter Berücksichtigung multipler endogener und exogener Belastungsfaktoren des weiblichen Beckenbodens. Zntralbl Gynäkol 120:176-182

14. Walters MD (1999) Retropubic operations for genuine stress incontinence. In: Walters MD, Karram MM, Urogynecology and reconstructive pelvic surgery. Mosby, St.Louis, 159-169

15. Milani R, Scalambrino S, Quadri G, Algeri M, Marchesin R (1985) Marshall-Marchetti-Kantz procedure and Burch colposuspension in the surgical treatment of female urinary incontinence. Br J Obstet Gynecol 92:1050-1053

16. Jarvis GJ (1994) Surgery for genuine stress incontinence. Br J Obstet Gynaecol 101:371-374

17. Alcalay M, Monga A, Stanton SL (1995) Burch colposuspension: a 10-20-year follow-up. Br J Obstet Gynaecol 102:740745

18. Petros P, Ulmsten U (1993) An integral theory and its methods for the diagnosis and the management of femal urinary incontinence. Scand J Urol Nephrol [Suppl] 153:1-93

19. Petros P, Ulmsten U (1990) An integral theory of female urinary incontinence. Experimental and clinical considerations. Acta Ostet Gynecol Scand 69 [Suppl 153]

20. Demirci F, Petri E (2000) Perioperative complications of Burch colposuspension. Int Urogynnecol J 11:170-175

21. Meschia M, Pifarotti P, Bernasconi F, Guercio E, Maffiolini M, Magatti F, Spreafico L (2001) Tension-free vaginal tape: analysis of outcomes and complications in 404 stress incontinent women. Int Urogynecol J Pelvic Floor Dysfunct 12 [Suppl 2]:24-27 
22. Jeffry L, Deval B, Brisan A, Soriano D, Darai E (2001) Objective and subjective cure rates after tension-free vaginal tape for treatment of urinary incontinence. Urology 58:702-706

23. Soulie M, Cuvillier X, Benaissa A, Mouly P et al (2001) The tension-free transvaginal tape procedure in the treatment of female urinary stress incontinence: A French prospective multicentre study. Eur Urol 39:709-715

24. Tamussino KF, Hanzal E, Kölle D, Ralph G, Riss PA (2001) Tension-free vaginal tape operation: Results of the Austrian registry. Obstet Gynecol 98:732-736

25. Bettin, S, Fischer W, Tunn R (2000) TVT-Plastik bei Harninkontinenz. Erfahrungen der Charité-Frauenklinik. Gynäkol Prax 24:305-320
26. Haylen BT, Lee LC (2000) Tension-free vaginal tape. What if it's too tight? Int Urogynecol J 11 [Suppl 1]:29

27. Klutke C, Siegel S, Carlin B, Paszkiewicz E, Kirkemo A, Klutke J (2001) Urinary retention after tension-free vaginal tape procedure: incidence and treatment. Urology 58:697-701

28. Wallwiener D, Grischke EM, Rimbach S, Maleika A, Kaufmann M, Bastert G (1995) Endoscopic colposuspension ("retziusscopy" versus laparoscopy). An effective extension of the surgical spectrum of stress incontinence? Geburtshilfe Frauenheilkd 55:235-239

29. Zubke W.,Schröter M, Wallwiener D (2001) TVT-zum Vorgehen in der Praxis. Geburtshilfe Frauenheilkunde 61:426-427 